\title{
Technique for Outdoor Test on Concentrating Photovoltaic Cells
}

\author{
Paola Sansoni, ${ }^{1}$ Daniela Fontani, ${ }^{1}$ Franco Francini, ${ }^{1}$ David Jafrancesco, ${ }^{1}$ \\ Giacomo Pierucci, ${ }^{2}$ and Maurizio De Lucia ${ }^{2}$ \\ ${ }^{1}$ CNR-INO Istituto Nazionale di Ottica, Largo E. Fermi 6, 50125 Firenze, Italy \\ ${ }^{2}$ Dipartimento di Ingegneria Industriale, Università di Firenze, Via di S. Marta 3, 50139 Firenze, Italy \\ Correspondence should be addressed to Paola Sansoni; paola.sansoni@ino.it
}

Received 2 September 2015; Accepted 4 October 2015

Academic Editor: Xudong Zhao

Copyright (C) 2015 Paola Sansoni et al. This is an open access article distributed under the Creative Commons Attribution License, which permits unrestricted use, distribution, and reproduction in any medium, provided the original work is properly cited.

\begin{abstract}
Outdoor experimentation of solar cells is essential to maximize their performance and to assess utilization requirements and limits. More generally tests with direct exposure to the sun are useful to understand the behavior of components and new materials for solar applications in real working conditions. Insolation and ambient factors are uncontrollable but can be monitored to know the environmental situation of the solar exposure experiment. A parallel characterization of the photocells can be performed in laboratory under controllable and reproducible conditions. A methodology to execute solar exposure tests is proposed and practically applied on photovoltaic cells for a solar cogeneration system. The cells are measured with concentrated solar light obtained utilizing a large Fresnel lens mounted on a sun tracker. Outdoor measurements monitor the effects of the exposure of two multijunction photovoltaic cells to focused sunlight. The main result is the continuous acquisition of the $V$ - $I$ (voltage-current) curve for the cells in different conditions of solar concentration and temperature of exercise to assess their behavior. The research investigates electrical power extracted, efficiency, temperatures reached, and possible damages of the photovoltaic cell.
\end{abstract}

\section{Introduction}

To exploit the recent improvements in the development of photovoltaic (PV) cells and new materials for solar applications, it is important to test them both in laboratory and with direct exposure to the sun. The optical characterization of PV cells, optical components, and material samples can be performed using solar simulators [1-6]. For measurements on photovoltaic cells [7] the solar simulator usually needs to be suitably modified from a commercial product in order to reduce the output beam size $[8,9]$. The solar divergence is hardly reproduced by solar simulators, while measurements with solar trackers [10] consent to replicate the real operative conditions. Alternatively, laboratory tests can be performed using a solar divergence collimator [11] that exactly reproduces the sun's divergence, thus permitting a precise evaluation of optical parameters and optical behavior of solar components. Analogously solar rays, concentrated over a sample, allow to study the optical properties and performance of PV cells or other components applicable to solar installations.
The laboratory test of PV cells makes extensive use of simulators having the characteristic of reproducing the intensity and spectrum of natural sunlight [12-14]. When the cells to be tested are of concentration type, these devices must provide an adequate amount of light, even hundreds of times greater than the natural one. The technology used in these devices employs very powerful lamps appropriately filtered to reproduce the solar spectrum and optical systems capable of concentrating this light on a target of few squared centimeters $[3,15,16]$. The cost of these solar simulators, however, is very high and the large dimensions of the device hardly permit its allocation on a normal laboratory table. In addition, if the light source used has a power of several hundred kW also a system for disposal of the ozone gas produced by the lamp must be arranged. Alternatively, for concentrated photovoltaics, pulsed systems can be employed: they reach considerable powers but only for short time intervals [17-19].

The test methodology proposed in this paper uses solar light instead of a lamp and a Fresnel lens to concentrate light on the PV cell. The device is equipped with a solar tracking 
system, which ensures the continuity of the measurement, and with accessories that allow to stabilize the temperature of the cell under test. It is extremely useful for their practical application to experiment with solar photocells exposed to concentrated sunlight, analyzing their behavior.

An experimentation on two multijunction photovoltaic cells is performed for their application in a cogeneration system for solar energy exploitation. This system includes a linear parabolic concentrator, which focuses the light over row of PV cells, located on a side of a tube with rectangular section. The photocells are squared with dimensions $10 \times 10 \mathrm{~mm}$. The working principle of this cogeneration system consists in furnishing both electric energy and hot water: the energy is obtained through the PV cells, which are cooled by the water flowing on the tube; the water is heated using the same fluid.

The system is optically designed using ray-tracing simulations carried out with the calculation program Zemax-EE by Radiant Zemax. The working conditions of the photocell (solar concentration, incident power density, focused light distribution, image dimension, etc.) are estimated by simulating the concentered light distribution in the image plane. The measurements parameters for the outdoor tests are then chosen on the basis of these simulations of the cogeneration system in order to reproduce the actual operative conditions. A preliminary characterization of the cells is carried out in laboratory, in a controllable and reproducible situation, to serve as reference for the field measurements. During the outdoor experimentation, in direct exposure to the sun, measurement conditions are monitored with controls similar to those made in laboratory. This control of the parameters during the actual operation of the solar device permits to assess the working temperature of the cells and possible damages of the system components.

Hence the main advantage of solar outdoor experimentation is to work in the real operating conditions of a solar installation. Insolation (solar irradiance) and ambient factors are not controllable but the outdoor test conditions can be surveyed and recorded by measuring proper physical quantities with appropriate instruments. Another benefit of using direct sunlight is to avoid the employment of artificial sources, lamps, or solar simulators, which can only try to reproduce spectral distribution, divergence and intensity of sunlight. Moreover the proposed device (essentially composed of a sun tracker) permits to test the photocell with its proper collection system (with primary collector and possible secondary optics).

\section{Device for Tests with Concentrated Sunlight}

The optical experimentation consisted in exposing the samples to solar light concentrated by a large Fresnel lens. The lens has a diameter of $470 \mathrm{~mm}$ and a focal ratio of about $F / 1$ and is installed on the solar tracking system shown in Figure 1.

The device in Figure 1 is a two-axis solar tracker, an equatorial mounting equipped with stepper motors; it was developed entirely within the Solar Collectors Laboratory of the National Institute of Optics [10]. The blue supporting frame is equipped with a series of pins to allow the rotation of the central perforated grid, which is constantly oriented

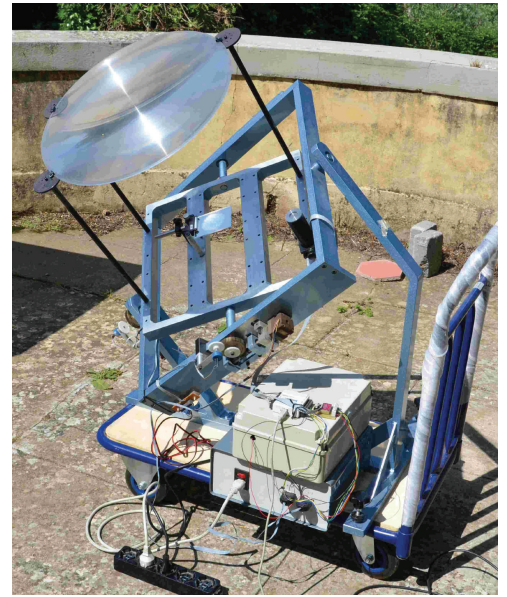

FIGURE 1: The sun tracker employed in the optical tests.

perpendicularly to the direction of solar rays. The lens is constrained to the grid by means of small columns, which hold it fixed at a certain distance and parallel to the grid plane. The sample is mounted on the same grid using a small support, with which it is possible to adjust the power density incident on the sample simply by varying the distance from the focus of the lens: by approaching the sample to the focus $F$ the power density increases, while increasing the distance from $F$ the power density is reduced. It has been verified that with this Fresnel lens it is possible to achieve power density levels of about $90 \mathrm{~kW} / \mathrm{m}^{2}$ in the proximity of the focal point.

The tracking technique utilizes a sun pointer [10], whose scheme is based on the principle of the pinhole camera: in fact it is a pinhole camera without lenses equipped with a fourquadrant photodiode. Sunlight enters the pinhole and illuminates the sensor; a software processes the signal arriving from each quadrant. The pointer is perfectly aligned with the solar rays' direction when the four signals are equal. The imbalance between the signals determines the misalignment of the center of gravity of the solar image with respect to the sensor. The same software provides to actuate the motors of the tracker until the solar image is equally distributed between the four quadrants, meaning that the tracker is aligned with the sun.

\section{Laboratory Determination of the Lens-Cell Distance}

To ensure proper operation, as well as to prevent damage of thermal type, a photovoltaic cell must be uniformly illuminated. The Fresnel lens used, visible in Figure 1, produces a spot with diameter of a few millimeters on the focal plane. Thus placing the cell in the vicinity of the lens focus would generate on the sensitive surface a density gradient of sufficient power to damage the photocell itself. Some preliminary measurements are performed in laboratory with the purpose of determining the suitable positions for the cell in order to have an acceptable uniformity of illumination.

A schematic view of the laboratory setup used is shown in Figure 2: it is a solar divergence collimator [11]. The optical 


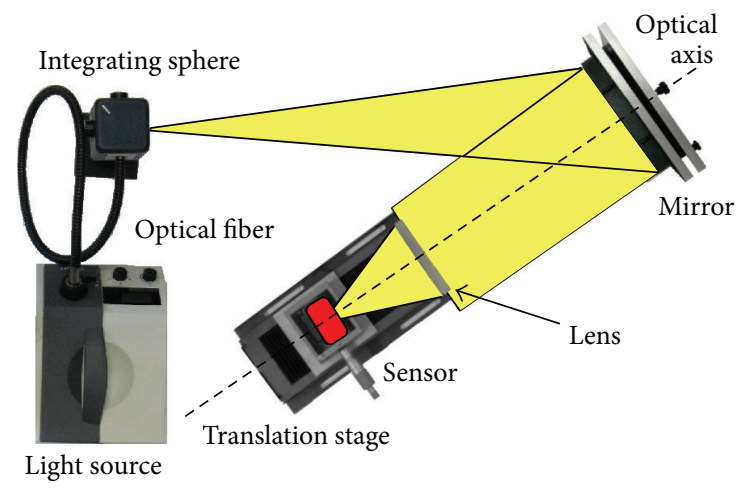

FIGURE 2: Scheme of the setup for the tests in laboratory.

system, constituted by source system, integrating sphere and mirror, produces a luminous beam with solar divergence of about $240 \mathrm{~mm}$ in diameter. The beam illuminates the lens and is concentrated on the focal plane. The sensor used for the measurements is positioned on the optical axis after the lens. The sensor is mounted on a linear micrometric shifter with excursion along the optical axis, in order to be able to vary the distance between sensor and lens. Since the diameter of the beam incident on the lens is about $250 \mathrm{~mm}$ (widened due to the divergence) and the lens diameter is $470 \mathrm{~mm}$, the laboratory setup of Figure 2 can illuminate only a portion of the lens. The measurements are then carried out by separately examining different areas of the large Fresnel lens.

The first optical analysis is devoted to determine the focal length of the Fresnel lens [20-22]. The focal distance can be defined and consequently measured in various ways; in this case it is assessed with the purpose of using this value in the outdoor tests to place the PV cell. The focal distance is measured from the lens in the point where the lens concentrated the maximum of power density. A first estimate is visually obtained using an opaque target. A more precise measurement is realized by placing a photodiode on the micrometric shifter; the focal plane is identified as the plane where the photodiode detects the maximum signal. The focal length so determined is equal to $460 \pm 3 \mathrm{~mm}$ : it is almost equal to the Fresnel lens diameter, thus confirming the focal ratio near $F / 1$ [22].

In order to evaluate the uniformity of illumination a CMOS camera is mounted on a shifter. The camera sensor has dimensions $7.74 \times 10.51 \mathrm{~mm}$, so the size is similar to that of the $\mathrm{PV}$ cell under examination, which is $10 \times 10 \mathrm{~mm}$. The CMOS camera acquired images of the central portion of the beam at different distances from the focal point. These images are used to qualitatively evaluate the suitable distance at which the area of the cell results illuminated with sufficient uniformity. In general, when the image plane is displaced from the focal plane the luminous spot results enlarged; it becomes more uniformly illuminated and the solar concentration decreases. Referring to the distance $d_{S}$ between cell plane and focal plane, the cell position for the outdoor tests is chosen depending on the solar concentration obtained: for $d_{S}=30 \mathrm{~mm}$ there is an optimal concentration, while for $d_{S}=40 \mathrm{~mm}$ the concentration is acceptable. When $d_{S}=30 \mathrm{~mm}$ an area of

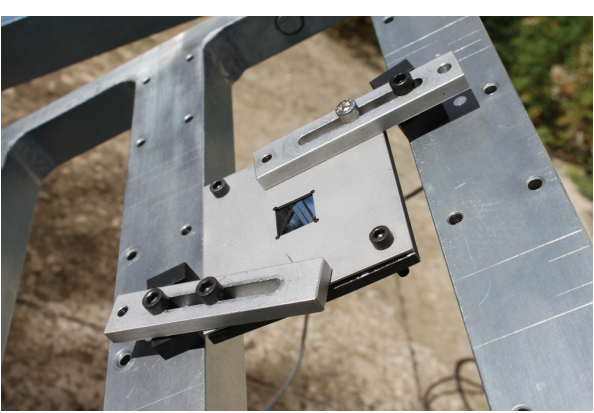

Figure 3: Optical system to protect the PV cell.

$10 \times 10 \mathrm{~mm}$ results fully illuminated, but for $d_{S}=40 \mathrm{~mm}$ the image shows a good uniformity over the entire cell area.

It should be noted that in the experiments in laboratory only a side portion of the lens is illuminated, while in the field tests the lens is completely illuminated. Therefore in the outdoor tests both a greater width of the spot and a higher quality of the image are expected; so the overall conditions appear to be a better situation than that obtained in laboratory at equal distance between lens and cell. From the laboratory measurements, the suitable distances $d_{S}$ for placing the sample are 30 and $40 \mathrm{~mm}$. In the field tests it is more practical to consider the distance $D$ between Fresnel lens and PV cell. Since the focal length of the Fresnel lens is $460 \mathrm{~mm}$, the related values are $D=430 \mathrm{~mm}$ for $d_{S}=30 \mathrm{~mm}$ and $D=$ $420 \mathrm{~mm}$ for $d_{S}=40 \mathrm{~mm}$.

\section{Setup for the Outdoor Tests and Exposure Procedure}

The exposure of the cells is carried out utilizing the sun tracker described in Section 2: the tracking system used in the tests is obtained introducing two modifications on the device of Figure 1. These changes consist in installing two accessories: a Peltier module and a pyrheliometer. The Peltier module is a thermoelectric cooler that uses the Peltier effect. This module, which is necessary for the cooling of the cell, is installed on the perforated grid, and the cell is applied on the module itself. The second modification concerns the installation of a pyrheliometer for measuring the direct component of the solar radiation during the exposure. The pyrheliometer is an instrument that measures the direct beam solar irradiance.

At the considered lens-cell distances ( 420 and $430 \mathrm{~mm}$ ) the size of the illuminated area is much larger than that of the cell; hence there is the risk that sensitive parts of the board are hit by concentrated light with high power density. To avoid problems the protection system illustrated in Figure 3 is realized and mounted: it includes a reflective truncated pyramid surrounded by a squared screen. The truncated pyramid is composed only of reflection elements, which are four mirrors with trapezoidal shape. The smaller squared base of the truncated pyramid has the dimensions of the cell. Therefore the reflective truncated pyramid is mounted on the grid of the tracker with the bottom aperture placed exactly 


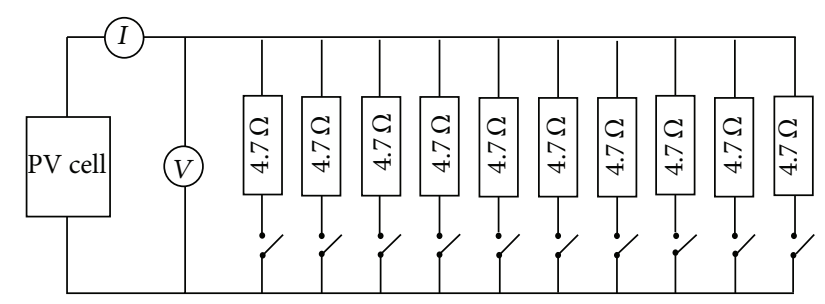

Figure 4: Electrical scheme of the variable load applied to the cell to determine the $V$ - $I$ curve.

over the cell, so as to limit the illumination area to the cell itself.

The cell temperature during solar exposure is controlled by the Peltier module. The actual temperature is recorded, for the whole test duration, acquiring the values given by a thermocouple. To perform the measurement, the probe is applied on the lateral edge of the sample, and the cell is positioned so that the edge of the illuminated area is as close as possible to the probe. This solution is chosen because it is impracticable to apply the probe directly on the illuminated area, as this would involve the direct exposure of the probe to the focused light, greatly influencing the measurement and probably damaging the probe itself. During most of the tests the temperature of the cell is kept at relatively low values compared to those of the expected working conditions (about 70$80^{\circ} \mathrm{C}$ ). Only in one case it is increased for testing the operating of the cell and of the whole system at different temperatures.

The signal of the pyrheliometer is always acquired by a NI-DAQ card throughout the solar exposure. The measurement gives the value of solar irradiance $E_{\text {sun }}$ on the basis of the conversion factor provided by the manufacturer.

A variable resistive load is applied to the terminals of the PV cell; its circuit diagram is shown in Figure 4. The switches shown in the diagram are manually operated in sequence, inserting the resistors in parallel. In total there are ten resistors of identical value of $R=4.7 \Omega$. At each insertion the load value decreases according to $R / N$, where $N$ is the number of switches that are closed. The values of current $(I)$ and voltage $(V)$ across the cell are read with a pair of digital volt-amperometers.

The density of solar power incident on the sample is regulated by varying the distance between lens and grid, where reflective truncated pyramid, PV cell, and board are mounted. For the placement of the sample, the reference parameter is not the power density on the cell, but the lens-cell distance, since the main concern is to illuminate the active surface of the cell as uniformly as possible. The power density on the cell is then obtained through subsequent concentration measurements.

The optical tests are executed following a repeatable procedure in exposing the samples to solar concentrated light: the main steps of this exposure procedure are summarized below. Once the tracker is aligned with the sun, the lens-cell distance is defined based on the value of power density that one wishes to impinge on the cell. The power density can be checked with a calibrated radiometer Ophir Nova, moving the head along the optical axis. The value of power density is assumed constant for the whole duration of solar exposure. The sample is mounted at the selected distance and kept exposed to solar concentrated light for a few hours. During sample exposure, at regular intervals, $V-I$ curves characterizing the cell are acquired (by the volt-amperometers), while cell temperature (using the thermocouple) and solar irradiance (with the pyrheliometer) are continuously recorded.

\section{Measurements of Solar Concentration}

Concentration measurements are executed using a calibrated radiometer Ophir Nova. This measurement is performed for both lens-cell distances $D$ considered, 420 and $430 \mathrm{~mm}$. It allows to determine the geometric factor $C$ of concentration of the Fresnel lens. The concentration factor [23] is defined as the ratio between the power density $E_{\text {cell }}$ incident on the cell, which is the light focused by the lens, and the power density $E_{1 \text { sun }}$, where "1sun" refers to a measurement performed without concentration:

$$
C=\frac{E_{\text {cell }}}{E_{1 \text { sun }}} .
$$

The measurement procedure employed is as follows. The radiometer measures the optical power $P_{1 \text { sun }}$ incident on the sensor associated to 1 sun. The corresponding power density is obtained by dividing this value by the area $A_{\text {det }}$ of the detector:

$$
E_{1 \text { sun }}=\frac{P_{1 \text { sun }}}{A_{\mathrm{det}}} .
$$

With the same instrument the optical power $P_{\text {cell }}$ is measured in correspondence with the cell, removing the support of the cell and replacing it with the sensor of the radiometer, keeping the rest of the setup unchanged. The power density on the cell $E_{\text {cell }}$ is obtained by dividing the optical power by the area $A_{\text {cell }}$ of the PV cell, equal to $100 \mathrm{~mm}^{2}$ :

$$
E_{\text {cell }}=\frac{P_{\text {cell }}}{A_{\text {cell }}} .
$$

For the latter measurement it is not binding to know the illuminated area of the detector; it is sufficient that it captures all of the light exiting from the bottom aperture of the reflective truncated pyramid. This aperture has in fact the same shape and size of the cell; therefore it can be assumed that all the light coming out from it illuminates the cell, if this is placed in contact with the bottom aperture of the truncated pyramid.

The factor $C$ is determined for both lens-cell distances considered. Knowing the concentration $C$, it is easy to calculate the power density $E_{\text {cell }}$ incident on the cell at the time of exposure based on the value of solar irradiance $E_{\text {sun }}$ obtained using the pyrheliometer:

$$
E_{\text {cell }}=C \cdot E_{\text {sun }}
$$

\section{Outdoor Tests and Results}

The results of cell characterization are discussed and compared only for two exemplificative solar cells, to evidence 
their different behavior and values. These two samples are tested exposing them to concentrated sunlight for a determined time interval. In order to obtain a characterization of each sample the $V-I$ (voltage-current) curves are acquired. For having a more complete information about the photocell behavior, the $V-I$ curves are measured in different conditions, varying exposure time, concentration, and cell temperature. The outdoor experimentation is carried out in condition of clear sky. The purpose of this analysis is to show the differences in behavior between two samples of the same type of multijunction PV cell, indicated as Cell_A and Cell_B.

This section presents the $V-I$ curves acquired in the various tests performed outdoor. To complete this optical characterization of the cells, some other significant data are acquired together with the values of voltage $V$ and current $I$. These parameters, characterizing the tests, are

(i) measurement time, with respect to the starting time $(t=0)$, in min: $t$;

(ii) power density incident on the cell in $\mathrm{kW} / \mathrm{m}^{2}: E_{\text {cell }}$;

(iii) optical power incident on the cell in W: $P_{\text {cell }}=E_{\text {cell }}$. $A_{\text {cell }}$;

(iv) cell temperature in ${ }^{\circ} \mathrm{C}$ : $T_{\text {cell }}$;

(v) open-circuit voltage in Volt: $V_{\mathrm{OC}}$;

(vi) maximum electrical power extracted in $\mathrm{W}: P_{\text {out }}$.

All the detections are made using calibrated instruments in order to limit the uncertainty of the final result below $10 \%$.

The cell is squared with side $10 \mathrm{~mm}$; the area of the photocell $A_{\text {cell }}$ is $100 \mathrm{~mm}^{2}$. The cell temperature is approximated to the temperature measured on the board by the thermocouple. The approximation is justified by the fact that the probe is positioned very close to the cell and the heat exchange in the space between the two is significant. The open-circuit voltage $V_{\mathrm{OC}}$ is the voltage measured in the absence of external load. It corresponds to the maximum value of the voltage and is given by the intersection of the $V-I$ curve with the abscissa axis $(I=0)$.

Sections 6.1 and 6.2 separately present the results of the outdoor characterization for Cell_A and Cell_B, while Section 6.3 describes the results obtained varying the temperature of the cell. The $V-I$ plots represent the characterization of each cell at different values of incident power density $\left(E_{\text {cell }}\right)$. The tables report, for each $V-I$ curve, some parameters measured during the characterization of the cell.

\subsection{Results for Cell_A}

Test_1. Specifications are as follows: lens-cell distance: $420 \mathrm{~mm}$; exposure duration: 3 hours; sample: Cell_A.

Test_2. Specifications are as follows: lens-cell distance: $430 \mathrm{~mm}$; exposure duration: 2 hours; sample: Cell_A.

\subsection{Results for Cell_B}

Test_3. Specifications are as follows: lens-cell distance: $420 \mathrm{~mm}$; exposure duration: 3 hours and $30 \mathrm{~min}$; sample: Cell_B.

Test_4. Specifications are as follows: lens-cell distance: $430 \mathrm{~mm}$; exposure duration: 3 hours; sample: Cell_B.

As can happen in outdoor tests, the conditions of solar illumination have changed in the third hour of Test_4: this modification of input power is visible in column 4 of Table 4 and in Figure 8, corresponding to a lower $V$ - $I$ curve.

The results reported in Sections 6.1 and 6.2 represent the characterization of two multijunction photovoltaic cells performed exposing them to concentrated sunlight. The tests considered exposure times $t$ up to 3.5 hours and lenscell distances $D$ selected in order to have the required concentration of solar light. At $D=430 \mathrm{~mm}$ the $10 \times 10 \mathrm{~mm}$ cell is entirely illuminated and the concentration $C$ is optimal (circa 150). For $D=420 \mathrm{~mm}$ the cell is fully and uniformly illuminated and $C$ is acceptable (about 100).

The principal characterization of the behavior of the optoelectronic component is illustrated by the $V-I$ curves: Figures 5 and 6 refer to Cell_A, while Figures 7 and 8 concern Cell_B. In all $V$ - $I$ curves the current $I$ decreases when the voltage $V$ increases; but for Cell_B the current maintains elevated values for $V<2.3 \mathrm{~V}$. This trend of the curves in Figures 7 and 8 represents a correct behavior for a photovoltaic cell.

Tables 1-4 summarize the working conditions measured in correspondence with the $V$ - $I$ curves plotted in Figures 5-8: incident power density $E_{\text {cell }}\left(\mathrm{kW} / \mathrm{m}^{2}\right)$, incident optical power $P_{\text {cell }}(\mathrm{W})$, cell temperature $T_{\text {cell }}\left({ }^{\circ} \mathrm{C}\right)$, open-circuit voltage $V_{\mathrm{OC}}$ $(\mathrm{V})$, and maximum extracted power $P_{\text {out }}(\mathrm{W})$. The parameters characterizing the tests are completed by the efficiency $\eta$.

How the cell performance changes with the exposure time is indicated in Tables 1-4 that present exactly the same parameters, while Table 5 examines the variation of cell temperature.

A significant parameter is the power density incident on the cell $E_{\text {cell }}$ : for both examined cells it results around $90 \mathrm{~kW} / \mathrm{m}^{2}$ for $D=420 \mathrm{~mm}$, while it is circa $150 \mathrm{~kW} / \mathrm{m}^{2}$ for $D=430 \mathrm{~mm}$ (there is an exception: $E_{\text {cell }}=82 \mathrm{~kW} / \mathrm{m}^{2}$ for $D=430 \mathrm{~mm}$ and $t=3 \mathrm{~h}$ ). The corresponding values for the optical power incident on the cell $P_{\text {cell }}$ are about $9 \mathrm{~W}$ for $D=$ $420 \mathrm{~mm}$ and around $15 \mathrm{~W}$ for $D=430 \mathrm{~mm}$ (but $P_{\text {cell }}=8 \mathrm{~W}$ after $3 \mathrm{~h}$ of exposure).

The open-circuit voltage $V_{\mathrm{OC}}$ is lower using Cell_A; it is around $2.1-2.3 \mathrm{~V}$ for both $D$ values, while the $V_{\mathrm{OC}}$ measured with Cell_B is higher, circa 2.7-2.8 V for both lenscell distances.

Probably the most significant parameter is the maximum electrical power extracted $P_{\text {out }}$. For Cell_A the values attained for $P_{\text {out }}$ are circa $0.9 \mathrm{~W}$ at $D=420 \mathrm{~mm}$ and $1.7-1.9 \mathrm{~W}$ at $D=430 \mathrm{~mm}$. Higher $P_{\text {out }}$ values are obtained with Cell_B: $2.7-3.3 \mathrm{~W}$ at $D=420 \mathrm{~mm}$ and $2.5-4.0 \mathrm{~W}$ at $D=430 \mathrm{~mm}$. These more satisfying data are in agreement with the correct characteristic curves in Figures 7 and 8: Cell_B works as a photocell and furnishes more electrical power. The bad 


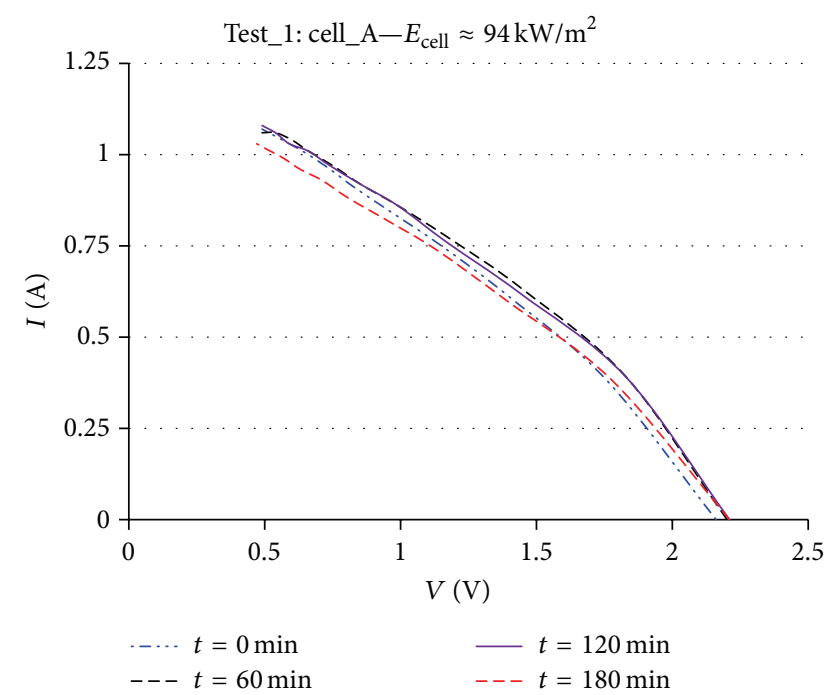

Figure 5: $V$ - $I$ curves acquired during Test_1, at the beginning and after 1, 2, and 3 hours of exposure.

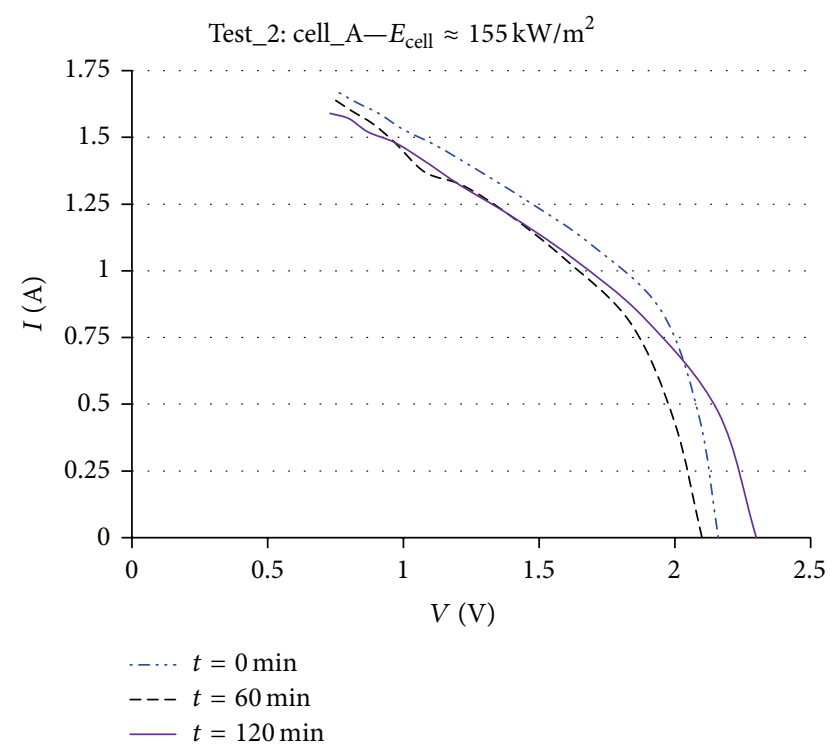

FIgURE 6: $V$ - $I$ curves acquired during Test_2, at the beginning and after 1 and 2 hours of exposure.

TABLE 1: Parameters characterizing Test_1.

\begin{tabular}{lcccc}
\hline$t(\min )$ & 0 & 60 & 120 & 180 \\
\hline$E_{\text {cell }}\left(\mathrm{kW} / \mathrm{m}^{2}\right)$ & 94.6 & 93.6 & 94.0 & 93.1 \\
$P_{\text {cell }}(\mathrm{W})$ & 9.46 & 9.36 & 9.40 & 9.31 \\
$T_{\text {cell }}\left({ }^{\circ} \mathrm{C}\right)$ & 38 & 43 & 41 & 40 \\
$V_{\text {OC }}($ Volt $)$ & 2.16 & 2.20 & 2.21 & 2.21 \\
$P_{\text {out }}(\mathrm{W})$ & 0.86 & 0.91 & 0.89 & 0.84 \\
$\eta\left(P_{\text {out }} / P_{\text {cell }}\right)$ & $9.1 \%$ & $9.7 \%$ & $9.5 \%$ & $9.0 \%$ \\
\hline
\end{tabular}

performance of Cell_A, with an improper $V$ - $I$ curve and low extracted power, suggests a possible damage of the sample.

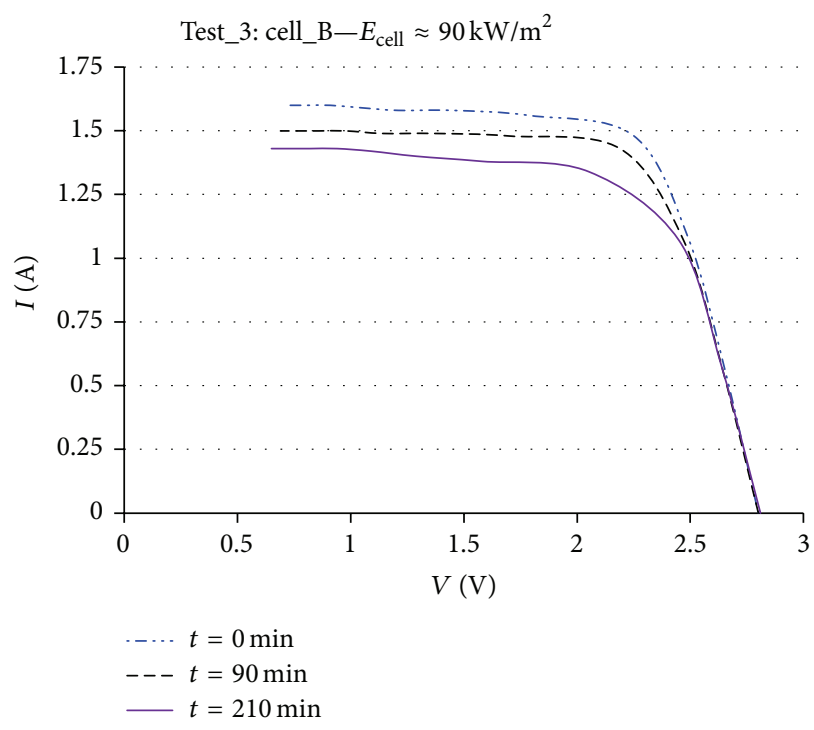

Figure 7: $V$ - $I$ curves acquired during Test_3, at the beginning and after 1 hour and $30 \mathrm{~min}$ and 3 hours and $30 \mathrm{~min}$ of exposure.

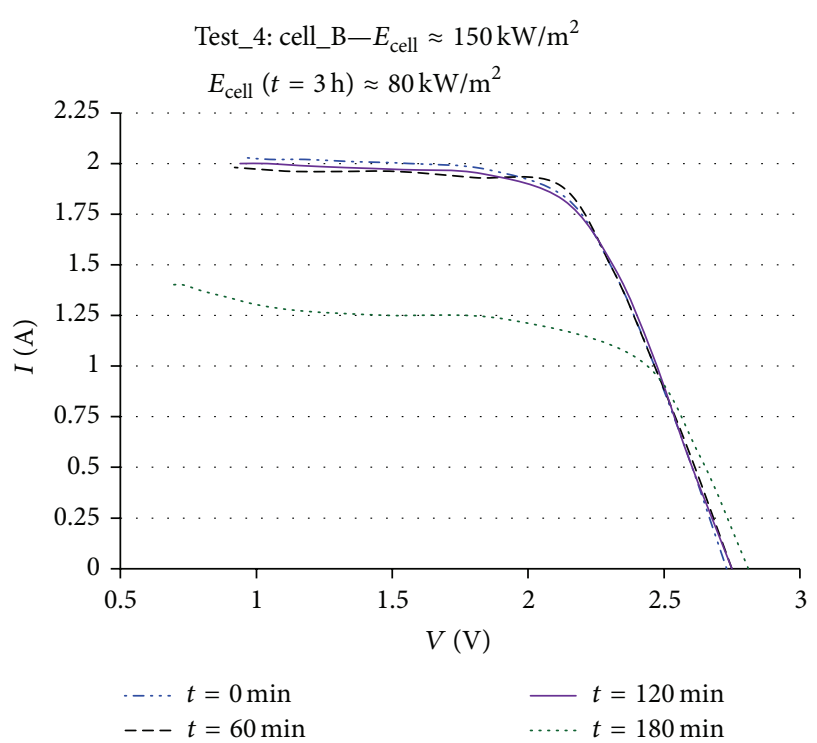

FIgURE 8: $V-I$ curves acquired during Test_4, at the beginning and after 1,2 , and 3 hours of exposure.

TABLE 2: Parameters characterizing Test_2.

\begin{tabular}{lccc}
\hline$t(\min )$ & 0 & 60 & 120 \\
\hline$E_{\text {cell }}\left(\mathrm{kW} / \mathrm{m}^{2}\right)$ & 157.1 & 157.7 & 152.6 \\
$P_{\text {cell }}(\mathrm{W})$ & 15.71 & 15.77 & 15.26 \\
$T_{\text {cell }}\left({ }^{\circ} \mathrm{C}\right)$ & 52 & 54 & 57 \\
$V_{\text {OC }}(\mathrm{Volt})$ & 2.16 & 2.10 & 2.30 \\
$P_{\text {out }}(\mathrm{W})$ & 1.86 & 1.68 & 1.70 \\
$\eta\left(P_{\text {out }} / P_{\text {cell }}\right)$ & $11.8 \%$ & $10.7 \%$ & $11.1 \%$ \\
\hline
\end{tabular}

A visual examination of Cell_A has confirmed the presence of damages. 
TABle 3: Parameters characterizing Test_3.

\begin{tabular}{lccc}
\hline$t(\mathrm{~min})$ & 0 & 90 & 210 \\
\hline$E_{\text {cell }}\left(\mathrm{kW} / \mathrm{m}^{2}\right)$ & 93.9 & 90.2 & 83.8 \\
$P_{\text {cell }}(\mathrm{W})$ & 9.39 & 9.02 & 8.38 \\
$T_{\text {cell }}\left({ }^{\circ} \mathrm{C}\right)$ & 45 & 45 & 42 \\
$V_{\text {OC }}($ Volt $)$ & 2.80 & 2.80 & 2.81 \\
$P_{\text {out }}(\mathrm{W})$ & 3.33 & 3.13 & 2.75 \\
$\eta\left(P_{\text {out }} / P_{\text {cell }}\right)$ & $35.5 \%$ & $34.7 \%$ & $32.8 \%$ \\
\hline
\end{tabular}

TABle 4: Parameters characterizing Test_4.

\begin{tabular}{lcccc}
\hline$t(\mathrm{~min})$ & 0 & 60 & 120 & 180 \\
\hline$E_{\text {cell }}\left(\mathrm{kW} / \mathrm{m}^{2}\right)$ & 152.6 & 147.7 & 148.3 & 81.6 \\
$P_{\text {cell }}(\mathrm{W})$ & 15.26 & 14.77 & 14.83 & 8.16 \\
$T_{\text {cell }}\left({ }^{\circ} \mathrm{C}\right)$ & 52 & 53 & 55 & 33 \\
$V_{\text {OC }}($ Volt $)$ & 2.73 & 2.75 & 2.75 & 2.81 \\
$P_{\text {out }}(\mathrm{W})$ & 3.92 & 4.01 & 3.88 & 2.48 \\
$\eta\left(P_{\text {out }} / P_{\text {cell }}\right)$ & $25.7 \%$ & $27.1 \%$ & $26.2 \%$ & $30.4 \%$ \\
\hline
\end{tabular}

TABle 5: Parameters characterizing Test_5.

\begin{tabular}{lcccc}
\hline$T_{\text {cell }}\left({ }^{\circ} \mathrm{C}\right)$ & 38 & 44 & 56 & 65 \\
\hline$E_{\text {cell }}\left(\mathrm{kW} / \mathrm{m}^{2}\right)$ & 89.1 & 89.1 & 89.1 & 89.1 \\
$P_{\text {cell }}(\mathrm{W})$ & 8.91 & 8.91 & 8.91 & 8.91 \\
$V_{\text {OC }}($ Volt $)$ & 2.17 & 2.15 & 2.12 & 2.11 \\
$P_{\text {out }}(\mathrm{W})$ & 0.72 & 0.70 & 0.68 & 0.70 \\
$\eta\left(P_{\text {out }} / P_{\text {cell }}\right)$ & $8.08 \%$ & $7.86 \%$ & $7.63 \%$ & $7.86 \%$ \\
\hline
\end{tabular}

The quantitative evaluation of the PV cell performance is given by the efficiency $\eta$ calculated in Tables $1-5$ as the ratio $P_{\text {out }} / P_{\text {cell }}$. The efficiency of Cell_B (26-36) is satisfactory while the efficiency for Cell_A (9-10) does not reach the expected $\eta$ value, confirming once again the malfunctioning of Cell_A. However Cell_B presents an unexpected behavior for the efficiency: the $\eta$ value (26-30) for higher concentration, at $D=430 \mathrm{~mm}$, is lower than for $D=420 \mathrm{~mm}(\eta=33-36)$, with inferior concentration. Analyzing the value of cell temperature $T_{\text {Cell }}$, it can be noted that even if the Peltier module is still active the temperature rises ten degrees in case of higher concentration. This effect can indicate that the efficiency of these cells is very sensitive to the cell temperature. Another aspect that could affect the cell efficiency is the fact, proved in laboratory, that for $D=420 \mathrm{~mm}$ the uniformity of the light beam is better than at distance $D=430 \mathrm{~mm}$. However the main dependence seems to be on temperature, as column 4 of Table 4 demonstrates: at $D=430 \mathrm{~mm}$, when the sun power decreases, reducing $T_{\text {Cell }}$, the efficiency improves.

6.3. Results Varying the Cell Temperature. A series of measurements is carried out in order to control the effects of the variation of the cell temperature, excluding the Peltier module and so allowing the temperature to rise. It is performed at the shorter lens-cell distance $D$, which corresponds to a lower concentration, in order to allow the measurement of

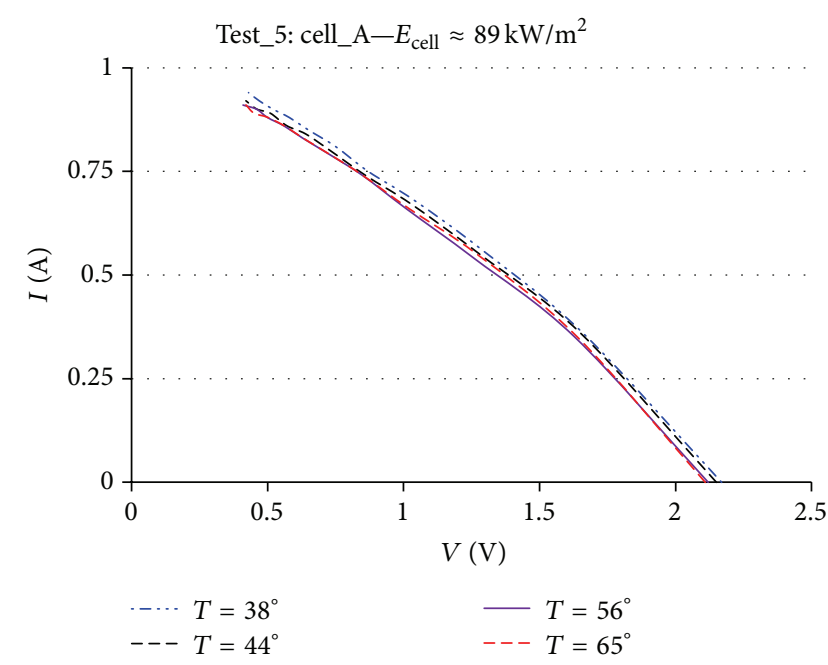

FIgURE 9: $V$ - $I$ curves acquired during Test_5, at different temperatures of the cell.

the temperature. At $D=430 \mathrm{~mm}$ the temperature variation would be too fast.

Test_5. Specifications are as follows: distance lens-cell: $420 \mathrm{~mm}$; duration of exposure: 15 minutes; other parameters: variation of the cell temperature; sample: Cell_A.

The temperature of the cell $T_{\text {Cell }}$ is a very important quantity. During the basic exposure tests at $D=420 \mathrm{~mm}$ (Test 1 and Test_3) the range of $T_{\text {Cell }}$ is $38-43^{\circ} \mathrm{C}$ for Cell_A and $42-$ $45^{\circ} \mathrm{C}$ for Cell_B. Higher temperatures are reached in the basic exposure tests at $D=430 \mathrm{~mm}$ (Test_2 and Test_4): the $T_{\text {Cell }}$ range is $52-57^{\circ} \mathrm{C}$ for Cell $\_$A and $52-55^{\circ} \mathrm{C}$ for Cell_B (except for $t=3 \mathrm{~h}$ when $T_{\text {Cell }}=33^{\circ} \mathrm{C}$ ). A dedicated test (Test_5), reported in Figure 9 and Table 5, examines the system behavior varying the cell temperature from $38^{\circ} \mathrm{C}$ to $65^{\circ} \mathrm{C}$ : the power density incident on the cell remains constant; the open-circuit voltage and the maximum electrical power extracted show only small fluctuations towards inferior values when $T_{\text {Cell }}$ increases.

\section{Conclusion}

Experimentation with direct exposure to sunlight is essential to evaluate the behavior of solar components in situations very similar to operative solar plants. In particular optoelectronic components for concentrating photovoltaic systems require an optical concentrator and a solar tracker to be examined in outdoor tests. When photocells are studied it is evident that the external measurements are useful because they can help to assess performance, functioning characteristics, and limitations of use. However some preliminary measurements in laboratory are suitable for choosing the geometric parameters appropriate for the outdoor tests.

The proposed methodology has the advantage of reproducing the real working conditions and the sun trackers allow to mount a custom optical systems (collector with possible secondary optics) to focus sunlight on the photocell, while solar simulators have their own optical system that focuses artificial light on the cell. The laboratory experimentation, using a solar divergence collimator [11], permits a more 
precise evaluation of the optical characteristics of the components, while solar simulators often have a divergence much larger than the solar rays, being aimed to reproduce the solar intensity.

The principal aim of this solar test is to characterize the photocells measuring voltage $(V)$ and current $(I)$ across the cell: the $V$ - $I$ curves indicate the behavior of the optoelectronic component.

Characterization curves and test parameters are compared for two exemplificative solar cells showing a completely different behavior. They are samples of the same type of photovoltaic cell and they are indicated as Cell_A and Cell_B. The cells are tested exposing them to concentrated solar light, focused by a large Fresnel lens. The experimentation is carried out for various exposure times $t$ and at different lens-cell distances $D$, selected in order to have the required concentration of sunlight.

Analogously to the parameters controls made in laboratory, during the field measurements it is interesting and practically useful to monitor the ambient and working conditions. These physical quantities represent the functioning parameters of the sample under test and the environmental state of the whole device for solar collection.

Comparing the results of the different exposure tests, it appears evident that Cell_B shows a correct behavior and an improved efficiency with respect to Cell_A. The $V-I$ curves for Cell $B$ have a trend similar to the theoretical one for a photocell, while the $V$-I curves for Cell_A deviate much from this trend. Also the performance of Cell_B is definitely better, in terms of both open-circuit voltage and electrical power extracted, with the same power density on the cell. The reason is that Cell_A is damaged.

In conclusion, at a distance of $420 \mathrm{~mm}$ from the Fresnel lens Cell_B reaches the maximum efficiency with values between 33 and 36 and the most uniform illumination of the cell is obtained. At a lens-cell distance of $430 \mathrm{~mm}$ Cell_B furnishes the maximum value of electrical power extracted, which is $4 \mathrm{~W}$.

For what concerns the behavior in time, the curves do not undergo significant changes for an exposure of 2-3 hours.

In the only test carried out by varying the temperature of the PV cell, the temperature increase does not produce changes on the $V-I$ curves or alteration of the parameters, in the regime of temperatures examined $\left(38-65^{\circ} \mathrm{C}\right)$.

This research is under development and further studies can investigate the behavior of other photovoltaic cells under different conditions of solar concentration.

\section{Conflict of Interests}

The authors declare that there is no conflict of interests regarding the publication of this paper.

\section{References}

[1] D. Hirsch, P. V. Zedtwitz, T. Osinga, J. Kinamore, and A. Steinfeld, "A new $75 \mathrm{~kW}$ high-flux solar simulator for hightemperature thermal and thermochemical research," Journal of Solar Energy Engineering, vol. 125, no. 1, pp. 117-120, 2003.
[2] K. R. Krueger, J. H. Davidson, and W. Lipiński, "Design of a new $45 \mathrm{kWe}$ high-flux solar simulator for high-temperature solar thermal and thermochemical research," Journal of Solar Energy Engineering-Transactions of the ASME, vol. 133, no. 1, Article ID 011013, 2011.

[3] D. S. Codd, A. Carlson, J. Rees, and A. H. Slocum, "A low cost high flux solar simulator," Solar Energy, vol. 84, no. 12, pp. 22022212, 2010.

[4] C. Domínguez, I. Antón, and G. Sala, "Solar simulator for concentrator photovoltaic systems," Optics Express, vol. 16, no. 26, pp. 14894-14901, 2008.

[5] J. Petrasch, P. Coray, A. Meier et al., "A novel $50 \mathrm{~kW} 11,000$ suns high-flux solar simulator based on an array of xenon arc lamps," Journal of Solar Energy Engineering, Transactions of the ASME, vol. 129, no. 4, pp. 405-411, 2007.

[6] S. H. Jang and M. W. Shin, "Fabrication and thermal optimization of LED solar cell simulator," Current Applied Physics, vol. 10, no. 3, supplement, pp. S537-S539, 2010.

[7] U. C. Pernisz, "Development of a standard test method for measuring photovoltaic cell performance," Solar Cells, vol. 7, no. 1-2, pp. 203-208, 1982.

[8] M. Bliss, T. R. Betts, and R. Gottschalg, "Advantages in using LEDs as the main light source in solar simulators for measuring PV device characteristics," in Reliability of Photovoltaic Cells, Modules, Components, and Systems, vol. 7048 of Proceedings of SPIE, Neelkanth G. Dhere, San Diego, Calif, USA, August 2008.

[9] S. Kohraku and K. Kurokawa, "New methods for solar cells measurement by LED solar simulator," in Proceddings of the $3 \mathrm{rd}$ World Conference on Photovoltaic Energy Conversion, vol. 2, pp. 1977-1980, May 2003.

[10] D. Fontani, P. Sansoni, F. Francini, D. Jafrancesco, L. Mercatelli, and E. Sani, "Pointing sensors and sun tracking techniques," International Journal of Photoenergy, vol. 2011, Article ID 806518, 9 pages, 2011.

[11] D. Fontani, P. Sansoni, E. Sani, S. Coraggia, D. Jafrancesco, and L. Mercatelli, "Solar divergence collimators for optical characterisation of solar components," International Journal of Photoenergy, vol. 2013, Article ID 610173, 10 pages, 2013.

[12] S. Kohraku and K. Kurokawa, "A fundamental experiment for discrete-wavelength LED solar simulator," Solar Energy Materials \& Solar Cells, vol. 90, no. 18-19, pp. 3364-3370, 2006.

[13] S. H. Jang and M. W. Shin, "Fabrication and thermal optimization of LED solar cell simulator," Current Applied Physics, vol. 10, no. 3, pp. S537-S539, 2010.

[14] D. Kolberg, F. Schubert, N. Lontke, A. Zwigart, and D. M. Spinner, "Development of tunable close match LED solar simulator with extended spectral range to UV and IR," Energy Procedia, vol. 8, pp. 100-105, 2011.

[15] W. Wang and B. Laumert, "Simulate a 'sun' for solar research: a literature review of solar simulator technology," KTH Literature Review 2014, Department of Energy Technology, Division of Heat and Power Technology, Royal Institute of Technology, Stockholm, Sweden, 2014.

[16] T. K. Mallick, "Indoor experimental characterisation of a three trough $50^{\circ}$ effective acceptance half-angle line-axis concentrating asymmetric compound parabolic photovoltaic concentrator using a continuous solar simulator," in Optics and Heat Transfer for Asymmetric Compound Parabolic Photovoltaic Concentrators for Building Integrated Photovoltaics, chapter 5 of $\mathrm{PhD}$ Thesis, Faculty of Engineering, Ulster University, Coleraine, UK, 2003. 
[17] C. Domínguez, I. Antón, and G. Sala, "Solar simulator for concentrator photovoltaic systems," Optics Express, vol. 16, no. 19, pp. 14894-14901, 2008.

[18] I. Antón, R. Solar, G. Sala, and D. Pachón, "IV testing of concentration modules and cells with non-uniform light patterns," in Proceedings of the the 17th European Photovoltaic Solar Energy Conference and Exhibition, pp. 611-614, 2001.

[19] W. Keogh and A. Cuevas, "Simple flashlamp I-V testing of solar cells," in Proceedings of the IEEE 26th Photovoltaic Specialists Conference, pp. 199-202, October 1997.

[20] R. Winston, J. C. Mińano, and P. Benítez, Nonimaging Optics, Elsevier Academic Press, Amsterdam, The Netherlands, 2005.

[21] J. C. Chaves, Introduction to Nonimaging Optics, CRC Press, Boca Raton, Fla, USA, 2008.

[22] A. Davis and F. Kühnlenz, "Optical design using fresnel lenses," Optik \& Photonik, vol. 2, no. 4, pp. 52-55, 2007.

[23] W. B. Stine and M. Geyer, Power from the Sun, 2001, http://www .powerfromthesun.net/book.html. 

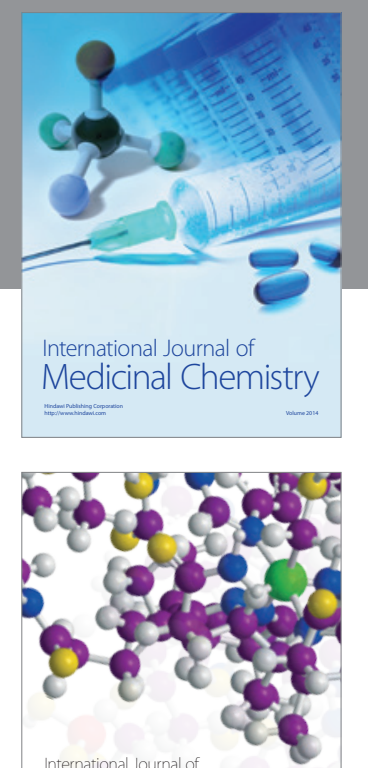

\section{Carbohydrate} Chemistry

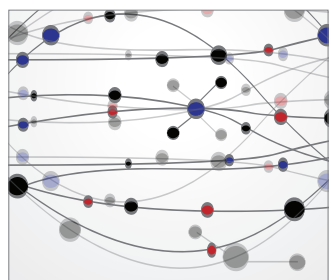

The Scientific World Journal
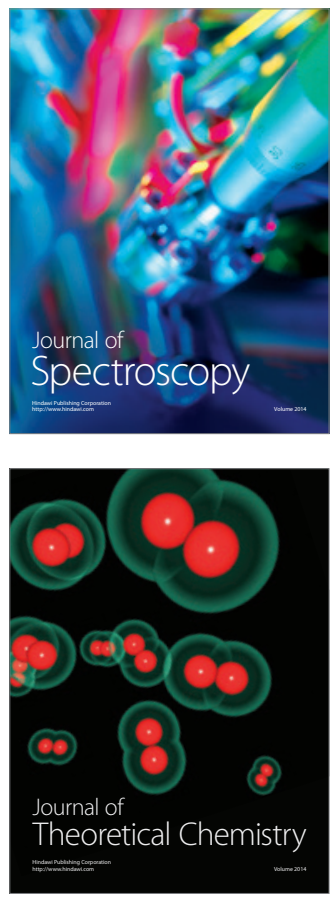
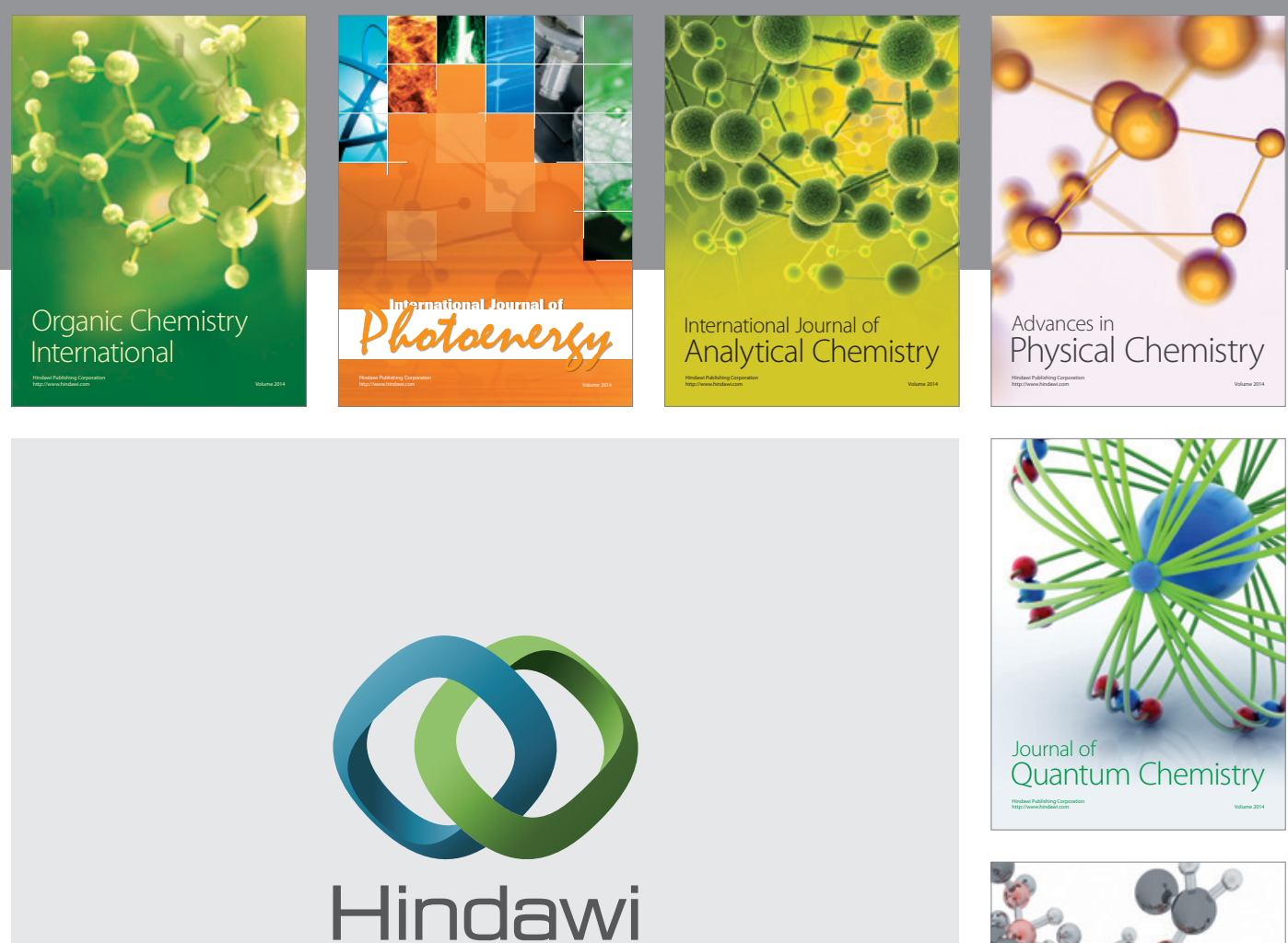

Submit your manuscripts at

http://www.hindawi.com

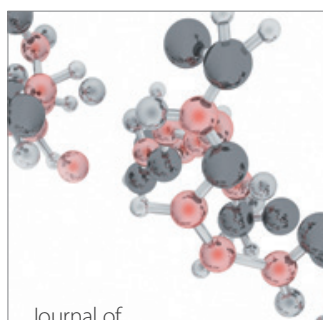

Analytical Methods

in Chemistry

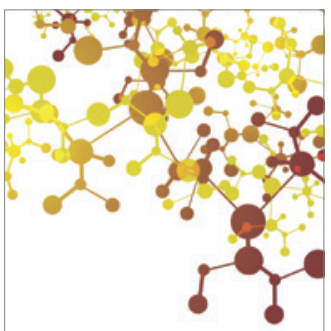

Journal of

Applied Chemistry

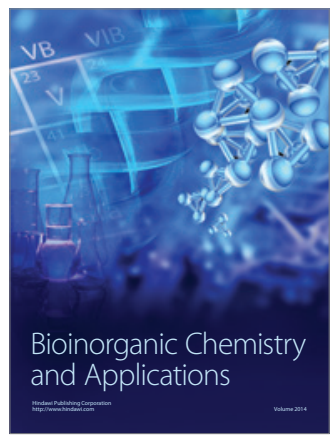

Inorganic Chemistry
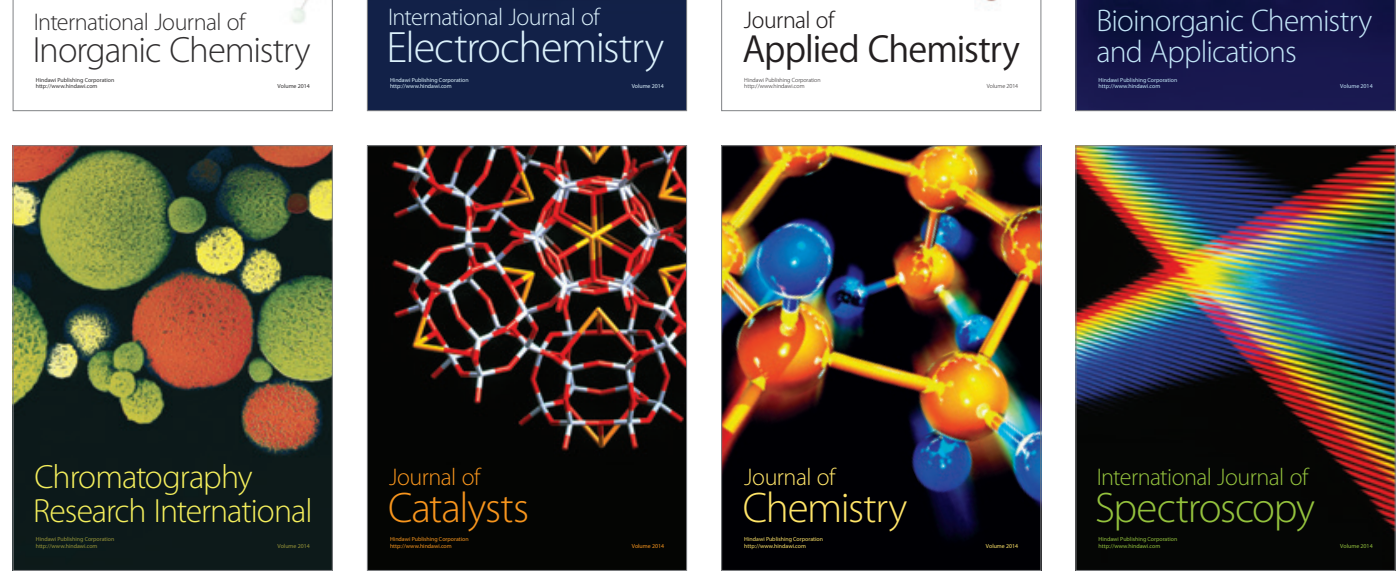